\title{
ASSESSMENT ON LEVEL OF INDOOR AIR QUALITY AT KINDERGARTENS IN AMPANG JAYA, SELANGOR, MALAYSIA
}

F. A. Sarijuddin' ${ }^{1}$, A. S. M. Saudi ${ }^{1,{ }^{*}}$, M. K. A. Kamarudin ${ }^{2}$, K. N. M. Isa ${ }^{1}$, M. Mahmud ${ }^{3}$, A. Azid $^{4}$, A. Balakrishnan ${ }^{1}$, I. F. Abu ${ }^{1}$, N. A. Amin ${ }^{1}$ and Z. I. Rizman ${ }^{5}$

${ }^{1}$ Faculty of Environmental Healthcare, University Kuala Lumpur MESTECH(UniKL), 43600 Kajang, Selangor, Malaysia

${ }^{2}$ East Coast Environmental Research Institute, Gong Badak Campus UnisZA, 21300 Kuala Nerus, Terengganu, Malaysia

${ }^{3}$ The Management School, Lancaster University, Bailrigg Lancaster LA1 4YX, Lancaster, United Kingdom

${ }^{4}$ Faculty of Bioresources and Food Industry, Universiti Sultan Zainal Abidin, 22200 Besut, Terengganu, Malaysia

${ }^{5}$ Faculty of Electrical Engineering, UniversitiTeknologi MARA, 23000 Dungun, Terengganu, Malaysia

Published online: 05 October 2017

\begin{abstract}
This study identify the air pollutant that occurs in the kindergartens, to measure the level of indoor air quality and also to analyze the association between indoor air quality patterns with respiratory health symptoms. Three kindergartens were selected based on types of building (single house, terraced 2 floors and refurbished commercial buildings).
\end{abstract}

Author Correspondence, e-mail: ahmadshakir@unikl.edu.my

doi: http://dx.doi.org/10.4314/jfas.v9i4s.45 
The exposure history and respiratory health symptoms data among respondent in the study area were being collected by using questionnaire. Sampling for IAQ also being conducted and parameters involved for this purposed included carbon monoxide, carbon dioxide, temperature and humidity. Result shows that there is no significant difference of IAQ level between all kindergartens except for temperature and humidity $(\mathrm{p} \leq 0.05)$. The respiratory health symptoms also showed that only phlegm and chest illness show the significant difference in all kindergartens which $(\mathrm{p} \leq 0.05)$.

Keywords:indoor air quality; children; kindergartens; allergy; respiratory.

\section{INTRODUCTION}

Since Malaysia government has made a policy where the proper early education for children is compulsory, the number of kindergarten which provides daily care and education keep increasing throughout the year [1]. As the number of children at the age 4 to 6 attending kindergarten in Malaysia is high compare to the past decades, the question on how safety the environment for these future leader continue to arise.Previous study has shown that there is significant association between poor indoor air quality and lung function among children in Selangor [2]. This study is similar with the finding where the concentration of indoor air pollutants has influence in increasing of symptoms of health problems among children in kindergarten [3]. However, the indoor air quality at the school facilities is poorly documented. Therefore, this study is timely as there is an urgent need for documented study on IAQ status in the education centers especially in the schools where the future leaders of our generation are trained.

\section{EXPERIMENTAL}

\subsection{Study Location and Study Design}

The study designs in this research are cross sectional study, where a complete assessment of IAQ and respiratory symptoms were conducted among children at three kindergartens in Ampang Jaya Selangor. All three kindergartens had difference building characteristics which are K1 single house, K2 terraced 2 floors and K3 refurbished commercial building. 


\subsection{Study Population}

A total of 97 children aged 4-6 years old were recruited from three kindergartens located at Ampang Jaya, Selangor. Study sample were selected among male and female children who attended the kindergartens. Respondents who fulfilled the inclusion criteria (children aged 4-6, healthy, enrolled in the preschooled not less than 4 months, full enrolment (45 hours/week) and free from any respiratory illness) were selected randomly to participate in this study.

\subsection{Questionnaire}

A set of modified questionnaire were adopted from The American Thoracic Society, 'Questionnaire ATS-DLD-C WHO (1982)' [9]. The questionnaire has been translated into Malay language and distributed in dual-language to the children's parents. The questionnaires were pre-tested with $10 \%$ of the total respondents from sample size. The purpose of questionnaire is to know the socio-economic background and health conditions of their children.

\subsection{Indoor Air Quality Measurement}

There are four indoor air characteristics that were monitored and measured. It used instrument in monitoring temperature, air humidity, carbon dioxide $\left(\mathrm{CO}_{2}\right)$ and carbon monoxide $(\mathrm{CO})$ which is Indoor Air Quality (IAQ) meter 7545 [6]. Then, the level of measurement was compared to the Department of Occupational Safety and Health (DOSH) 2010 and American Society for Heating, Refrigerating and Air Conditioning Engineers [10-11] to determine the level of IAQ concern.

The data collection was commenced on January 2017 to June 2017. The data was collected during the operation hours of kindergartens $(8 \mathrm{am}-5 \mathrm{pm})$ when the room was fully occupied by daily routines. The IAQ meter were placed on top of table within children breathing zone $(0.5-0.7 \mathrm{~m})$ off the ground level, out of children reach and away from the windows, doors and bookshelves [6].

\subsection{Statistical Analysis}

The data collected would be analyzed using computer software known as Statistical Package for Social Science (SPSS) Version 20.0. In order to identify the relationship and differences between indoor air pollutants concentrations and respiratory health of children, One-way 
ANOVA test and Chi-square test were used [2].

\section{RESULTS AND DISCUSSION}

\subsection{Sociodemographic Data of Respondents}

According to the result obtained from the questionnaire form, the answers of the sociodemographic of respondents were grouped into several categories. Table 1 shows the results from questionnaire which consists of children age, gender and type of housing, environmental tobacco smoking (ETS) exposure in their homes.

All the respondents were Malay with child between 4-6 years old. Most parents who participated in the questionnaire had mostly male children $(51.5 \%)$ and lived in single storey house $(39.2 \%)$. Almost $62.9 \%$ of the children had more than two siblings and $61.9 \%$ had air conditioner. As for the presence of pet in the house and the exposure of environmental tobacco smoke (ETS) in the house, the result showed that only $27.8 \%$ from the total respondents having pets at their home and $36.1 \%$ of them are exposed to the environmental tobacco smoke (ETS). Even though the information was accurately compiled, bias information could be resulted from parents' answers.

From the questionnaire distributed and obtained, most of the children lived in single house and having more than two siblings in their family. Contrast with the ventilation in the kindergartens, most of the children live with air conditioner at home. Other than that, from the results obtained, children are less exposed to the environmental tobacco smoke (ETS) at home and do not have a pet at home. 
Table 1. Descriptive analysis of respondents' sociodemographic data

\begin{tabular}{cccc}
\hline \multicolumn{2}{c}{ Characteristics } & n & \% \\
\hline Mean Age & $4-6$ years & & \\
Gender & Male & 50 & 51.5 \\
& Female & 47 & 48.5 \\
Type of Housing & Single house & 38 & 39.2 \\
& Private residential apartments & 31 & 32.0 \\
Have more than 2 siblings & Public residential apartments & 28 & 28.9 \\
Home ventilation & & 61 & 62.9 \\
& None & 37 & 38.1 \\
Presence of pets & Air-conditioner & 60 & 61.9 \\
& Yes & 27 & 27.8 \\
& No & 70 & 72.2 \\
ETS (cigarette) exposure at home & Yes & 35 & 36.1 \\
& No & 62 & 63.9 \\
\hline
\end{tabular}

*Descriptive analysis; $\mathrm{n}=97$

\subsection{Comparison of Indoor Air Quality among Kindergartens}

Indoor air qualities (IAQ) were measured to present a descriptive data of physical and chemical parameters. Table 2 shows that the mean of temperature and relative humidity also showed a significant difference with the result of $(F=8.987$ and $p=<0.001)$ and $(F=24.500$ and $\mathrm{p}=<0.001)$ respectively with $\mathrm{K} 1$ recorded the highest mean of temperature (29.358) and relative humidity (66.582) as compared to the other two kindergartens. However, the IAQ level of $\mathrm{CO}_{2}$ showed no significant difference among all three kindergartens which $(\mathrm{p}>0.05)$ with the result of $(\mathrm{F}=1.791$ and $\mathrm{p}=0.172)$. This also applicable to carbon monoxide $(\mathrm{CO})$, where the mean of carbon dioxide (CO) in $\mathrm{K} 2$ also higher compared to the other two kindergartens. The statistical analysis showed that there is no significant difference in $\mathrm{CO}$ $(\mathrm{F}=2.636, \mathrm{p}=0.077)$ between all three kindergartens.

Indoor air quality parameters were measured from three different kindergartens in this study. Temperature and relative humidity were recorded higher within $\mathrm{K} 1$, as compared to other two 
kindergartens. Department of Safety and Health [4] have stated that to feel comfortable, the temperature should be in the range of $23^{\circ} \mathrm{C}$ to $26^{\circ} \mathrm{C}$. Whereas, American Society of Heating, Refrigerating, and Air Conditioning Engineering (ASHRAE) Standard 62.1, indoor air humidity should be monitored between 30 to $65 \%$ for optimum comfort level. If the optimum comfort level is fail to achieved, it may create static build up and people will sense that their skin dry, whereas too much humidity will cause skin to feel sticky. High temperature and humidity can increase concentration of some indoor pollutants [5].

Statistical analysis showed that there is no significant difference in the $\mathrm{CO}$ and $\mathrm{CO}_{2}$ concentration within three kindergartens. Since the mean of $\mathrm{CO}_{2}$ did not exceed the local guidelines of $1000 \mathrm{ppm}$, the result is revealed the same with the previous study where the mean of the study is $726.7 \mathrm{ppm}$. The findings stated that the location of building was influenced by its surrounding environment overwhelmed by automobiles exhaust or nearby activities [6].

Table 2. Comparison of indoor air quality among kindergartens

\begin{tabular}{|c|c|c|c|c|c|}
\hline Variables & K1 & $\begin{array}{r}\text { K2 } \\
\text { Mean (SD) }\end{array}$ & K3 & $\mathbf{F}$ & P-Value \\
\hline \multirow[t]{2}{*}{$\mathrm{CO}$} & 0.333 & 0.600 & 0.526 & 2.636 & 0.077 \\
\hline & $(0.330)$ & $(0.454)$ & $(0.637)$ & & \\
\hline \multirow[t]{2}{*}{$\mathrm{CO}_{2}$} & 552.39 & 542.52 & 581.58 & 1.791 & 0.172 \\
\hline & $(44.173)$ & $(81.135)$ & $(117.457)$ & & \\
\hline \multirow[t]{2}{*}{ Temperature $\left({ }^{\circ} \mathrm{C}\right)$} & 29.358 & 27.379 & 28.771 & 8.987 & $<0.001^{*}$ \\
\hline & $(1.175)$ & $(1.398)$ & $(2.881)$ & & \\
\hline Relative Humidity & 66.582 & 58.485 & 60.694 & 24.500 & $<0.001 *$ \\
\hline$(\%)$ & $(3.363)$ & $(2.350)$ & $(7.469)$ & & \\
\hline
\end{tabular}

*ANOVA test; Significant at $\mathrm{p}(\leq 0.05)$

\subsection{Prevalence of Respiratory Health Symptoms}

There were five parameters of respiratory health symptoms assessed in this study. Those five parameters are identified using standardized and validated questionnaire, which were adopted from American Thoracic Society. The questions that were asked to the parents or guardian 
included cough, phlegm, wheezing, chest illness and allergy experienced by the children. The questionnaires were filled by the parents of children.

From Table 3, the Chi-square test showed that there were significant differences between phlegm and chest illness among respondents with $\left(\chi^{2}=9.540, p=0.008\right)$ and $\left(\chi^{2}=9.002\right.$, $\mathrm{p}=0.011$ ) respectively. Results showed that children from K3 reported higher prevalence of phlegm (35.5\%) as compared to children from K1 (6.1\%) and K2 (15.2\%). Meanwhile, children from K1 reported highest prevalence of chest illness (33.3\%) as compared to children from $\mathrm{K} 2$ and $\mathrm{K} 3$ which is $12.1 \%$ and $6.5 \%$ respectively.

Other symptoms such as cough, wheezing and allergy are commonly found among children, but there are no significant differences of the prevalence among three kindergartens as the result show $\left(\chi^{2}=1.065, p=0.587\right),\left(\chi^{2}=3.239, p=0.198\right)$ and $\left(\chi^{2}=9.540, p=0.008\right)$.

Although these three types of respiratory health symptoms have not showed a significant difference between kindergartens, most of the children reported for cough at all kindergartens. 15 out of 33 respondents have reported cough as the highest respiratory health symptoms suffered by the children attended K2, followed by K3 and K1 with the result 13 and 11 respectively. Wheezing also reported high among children attending K1 10 (30.3\%), K3 7 $(22.6 \%)$ but not for K2 which only 4 (12.1\%). In this study, the results indicated that the kindergartens failed to achieve the standard of temperature and relative humidity.

Occupants of the building often diagnosed with the sick building syndrome (SBS) that are caused by respiratory health symptoms. SBS symptoms include the eye, nose and throat irritation, dryness of mucous membrane and skin, chest tightness, wheezing, cough and dizziness [5]. Thus, it showed that occupants in K1, K2 and K3 high possibly suffering sick building syndrome. This is because SBS symptoms are more prevalent at high temperature. 
Table 3. Prevalence of respiratory health symptoms

\begin{tabular}{|c|c|c|c|c|c|}
\hline Variable & K1 & $\begin{array}{c}\text { K2 } \\
\text { Total (\%) }\end{array}$ & K3 & $\chi^{2}$ & P-Value \\
\hline \multicolumn{6}{|l|}{ Cough } \\
\hline Yes & $11(33.3)$ & $15(45.5)$ & 13 (41.9) & \multirow[t]{2}{*}{1.065} & \multirow[t]{2}{*}{0.587} \\
\hline No & $22(66.7)$ & $18(54.5)$ & $18(54.5)$ & & \\
\hline \multicolumn{6}{|l|}{ Phlegm } \\
\hline Yes & $2(6.1)$ & $5(15.2)$ & $11(35.5)$ & \multirow{2}{*}{9.540} & \multirow{2}{*}{$0.008 *$} \\
\hline No & 31 (93.9) & $28(84.8)$ & $20(64.5)$ & & \\
\hline \multicolumn{6}{|l|}{ Wheezing } \\
\hline Yes & $10(30.3)$ & $4(12.1)$ & 7 (22.6) & \multirow{2}{*}{3.239} & \multirow{2}{*}{0.198} \\
\hline No & $23(69.7)$ & $29(87.9)$ & $24(77.4)$ & & \\
\hline \multicolumn{6}{|c|}{ Chest Illness } \\
\hline Yes & $11(33.3)$ & $4(12.1)$ & $2(6.5)$ & \multirow[t]{2}{*}{9.002} & \multirow[t]{2}{*}{$0.011 *$} \\
\hline No & $22(66.7)$ & $29(87.9)$ & $29(93.5)$ & & \\
\hline \multicolumn{6}{|l|}{ Allergy } \\
\hline Yes & $11(33.3)$ & 7 (21.2) & $8(25.8)$ & \multirow[t]{2}{*}{1.259} & \multirow[t]{2}{*}{0.533} \\
\hline No & $22(66.7)$ & $26(78.8)$ & $23(74.2)$ & & \\
\hline
\end{tabular}

*Chi Square Test; Significant at $\mathrm{p}(\leq 0.05)$

\subsection{Association between Indoor Air Pollutants and Respiratory Health Symptoms}

As for statistical analysis, the parameter has been categorical into acceptable and non-acceptable limit stated in the Malaysia Code of Practice by DOSH. Based on the Chi-square test analysis, there is only one IAQ parameter and respiratory health symptoms believed to be related. The result showed that significant association between relative humidity and allergy in kindergartens which $p \leq 0.05$ with result of $p=0.046$. On the other hand, the other IAQ parameters showed no significant association are found for the other respiratory symptoms.

The previous study conducted in Malaysia showed that air pollutants can worsen childhood asthma even at low concentration. This became a concern considering that individual with asthma and allergies are potentially susceptible to indoor air contaminants [7]. This is similar 
with the result in 2002 where the dissatisfaction among children towards indoor air quality is correlated positively with allergen levels [8].

Table 4.Association between indoor air pollutants and respiratory health symptoms

\begin{tabular}{cccccc}
\hline IAQ & Cough & Phlegm & Wheezing & Chest Illness & Allergy \\
& & \multicolumn{3}{c}{$\chi^{\mathbf{2}}$ (p-value) } \\
Carbon & 1.272 & 0.024 & 0.723 & $1.448(0.229)$ & 0.001 \\
Monoxide & $(0.259)$ & $(0.876)$ & $(0.395)$ & & $(0.990)$ \\
$(\mathrm{CO})$ & & & & & \\
Carbon & 1.769 & 0.027 & 0.322 & $1.626(0.202)$ & 0.008 \\
Dioxide $\left(\mathrm{CO}_{2}\right)$ & $(0.180)$ & $(0.869)$ & $(0.570)$ & & $(0.929)$ \\
Relative & 0.895 & 0.007 & 1.047 & $0.022(0.881)$ & 3.961 \\
Humidity $(\%)$ & $(0.344)$ & $(0.932)$ & $(0.306)$ & & $\left(0.046^{*}\right)$ \\
Temperature & 0.764 & 0.526 & 0.946 & $0.020(0.888)$ & 0.634 \\
$\left({ }^{\circ} \mathrm{C}\right)$ & $(0.382)$ & $(0.468)$ & $(0.331)$ & & $(0.426)$ \\
\hline
\end{tabular}

*Chi Square Test; Significant at $\mathrm{p}(\leq 0.05)$

\section{CONCLUSION}

This study provides assessment on the level of indoor air quality and the relationship with respiratory health symptoms among children at kindergartens. Results from this study showed that exposure to indoor air pollutants were the cause of reported respiratory health symptoms. The result showed that the relative humidity and temperature were high at all kindergartens. Thus, it is showed that the recommendations of acceptable range by DOSH are failed to achieve.

This study indicated that the exposure to poor indoor air quality and the increase of levels of indoor air pollutants were the risk factors that had caused in increasing reports of respiratory health symptoms. As reported in this study, the level of relative humidity contributed to the presence of allergy which the level should be monitored in the range of $40 \%-70 \%$ for optimum level. The number of occupants, the location of kindergartens and the activities inside the building such as cooking and cleaning; and poor ventilation also can contribute to poor IAQ level and the increase of respiratory health problems among children [11-12]. 


\section{ACKNOWLEDGEMENTS}

This work has been supported in part by the Universiti Kuala Lumpur. The author would like to express her utmost gratitude to all the researchers who have contributed in this study. The author would also like to acknowledge the assistance and advice provided by supervisor; Dr Ahmad ShakirMohd Saudi.

\section{REFERENCES}

[1] Malaysian Educational Statistics. Educational planning and research division. Kuala Lumpur: Ministry of Education,2013

[2] Chua P C, Jalaludin J, Hamedon T R, Adam, N M. Indoor air quality assessment and lung functions among children in preschool at Selangor, Malaysia. Advances in Environmental Biology, 2015,9(9 SI):1-10

[3] Kamaruzzaman S N,Razak RA. Measuring indoor air quality performance in Malaysian government kindergarten. Journal of Building Performance, 2011, 2(1):70-79

[4] Department of Occupational Safety and Health (DOSH). Industry code of practice on indoor air quality. Putrajaya: Ministry of Human Resources, 2010

[5] Salleh N M, Kamaruzzaman S N, Sulaiman R, Mahbob N S. Indoor air quality at school: Ventilation rates and it impacts towards children- A review. In 2nd International Conference on Environmental Science and Technology, 2011, pp. 418-422

[6] Tezara C, Jalaludin J, Adam N M, JanuarParlaungan S. Assessment of children's health and indoor air contaminants of day care centre in industrial area. Iranian Journal of Public Health, 2014, 43(3):81-88

[7] Akinbami L, Edelman N H. The state of childhood asthma. Washington DC: U.S. Department of Health and Human Services, 2006

[8] Karlsson A. Comparison of four allergen-sampling methods in conventional and allergy prevention classrooms. Clinical and Experimental Allergy,2002, 32(12):1776-1781

[9] Chua P C, Jalaludin J, Hashim Z. School's indoor air quality and respiratory health implications among children. Advances in Environmental Biology, 2014,8(14):112-121

[10] American Society for Heating, Refrigerating and Air Conditioning Engineers (ASHRAE). Ventilation for acceptable indoor air quality, standard 62.1. Georgia: ASHRAE, 2007 
[11] Kamarudin M K, Nalado A M, Kasmuri A, Toriman M E, Juahir H, Umar R, Jamil N R, Saudi A S, Rizman Z I, Gasim M B, Hassan A R. Assessment of river plan changes in Terengganu River using RS and GIS method. Journal of Fundamental and Applied Sciences, $2017,9(2 S): 28-45$

[12] Saudi A S, Kamarudin M K, Ridzuan I S, Ishak R, Azid A, Rizman Z I. Flood risk index pattern assessment: Case study in Langat river basin. Journal of Fundamental and Applied Sciences, 2017, 9(2S):12-27

\section{How to cite this article:}

Sarijuddin F A, Saudi A S M, Kamarudin M K A, Isa K N M, Mahmud M, Azid A, Balakrishnan A, Abu I F, Amin N A, Rizman Z I. Assessment on level of indoor air quality at kindergartens in ampang jaya, selangor, malaysia. J. Fundam. Appl. Sci., 2017, 9(4S), $801-811$. 